\title{
Membrane Processes in Waste Treatment for Chemical and Nuclear Industries: Recent Advances
}

\author{
A. K. Pabby ${ }^{1 * *}$ \& A. M. Sastre ${ }^{2}$ \\ ${ }^{1}$ PREFRE, BARC Complex, Nuclear Recycle Board, BARC, Tarapur, Distt. Thane, 401502, Maharashtra, India \\ ${ }^{2}$ Department d'Enginyeria Química, Universtat Politècnica de Catalunya, ETSEIB, Av. Diagonal 647, 08028 \\ Barcelona, Spain
}

\begin{abstract}
Membrane technologies have seen a significant growth and increase in application in the last two decades. Membrane systems are now available in several different forms and sizes, each uniquely fitting a particular need and application. With the growing confidence to tailor-make membranes with desired characteristics, the applications can be extended to the separation / decontamination of a number of aqueous streams in chemical engineering or in the nuclear fuel cycle. The chemical and engineering communities are already paying significant attention to the quest for technologies that would lead us to the goal of technological sustainability. Amongst the various separation techniques, membrane based separation methods are getting increasingly popular due to factors such as high efficiency, and low in power consumption and easy scale-up due to a compact design etc. Also, in a modern approach, membrane contactors have proved to be an efficient contacting device, due to their high area per unit volume that results in high mass transfer rates. They are not only compact but also eliminate several of the problems faced in conventional processes such as ion exchange, solvent extraction, and precipitation.
\end{abstract}

Keywords: Membrane processes, reverse osomosis, nuclear industry, waste treatment, hollow fiber contactor

\subsection{INTRODUCTION}

A continuous research work on membrane properties and fundamental aspects of transport phenomena in various membrane operations is important for the future of membrane science and technology. There is a need for both basic and applied research to develop new membranes with improved properties and new membrane processes [1]. These processes are well suited for utilization in combination with many conventional separations in chemical and nuclear industry for treatment and processing of different liquid

\footnotetext{
* Corresponding to: A. K. Pabby (email: dranilpabby@gmail.com)
}

streams. The pressure driven membrane processes have an immense potential from the point of view of nuclear waste processing worldwide [2]. Range of pressure membrane processes is shown in Figure 1. A membrane separation system separates an influent stream into two effluent streams known as the permeate and the concentrate. The permeate is the portion of the fluid that has passed through the semipermeable membrane, whereas the concentrate stream contains the constituents that have been rejected by the membrane. In general, the introduction of these membrane processes has reduced waste treatment costs, improved quality of water discharged to the environment, and increased the possibility of recycling treated water. 


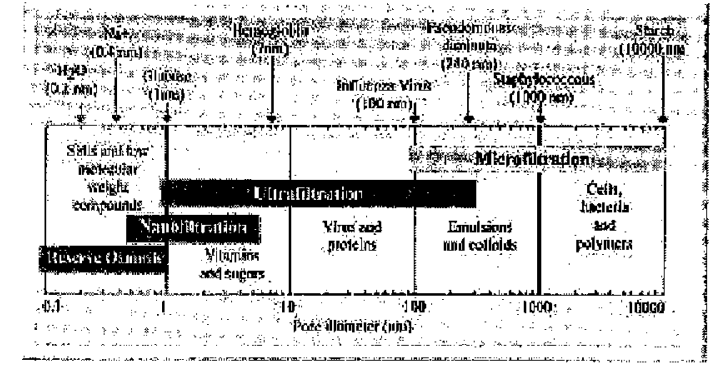

Figuxe 2 Range of pressure-driven membrane separation processes

Successful design and operation of a membrane system requires a collective commitment and dedicated teamwork by the system designers, operators, and the membrane suppliers. Membrane operations, with their intrinsic characteristics of efficiency and operational simplicity, high selectivity and permeability for the transport of specific components, compatibility between different membrane operations in integrated systems, low energetic requirement, good stability under operating conditions and environment compatibility, easy control and scale-up, and large operational flexibility, represent an interesting answer for the rationalization of chemical productions. The example is already set by experts in the field of membrane science and technology by installing world's largest desalination plant in Ashkelon, Israel which is now providing and selling $165000 \mathrm{~m}^{3}$ of water per day (Figure 2) [3]. This paper presents the overview of the different membrane technologies and their commercial applications in chemical and nuclear industries including current scenario including future challenges of these techniques applied world wide. Authors also cover some of the results obtained in his laboratory using concentration and pressure driven based membrane techniques for treating waste generated by radioactive plants. Attempts are made to focus future progresses in membrane engineering. Finally, analytical application of membrane techniques are also presented.

\subsection{PRESSURE AND CONCENTRATION DRIVEN MEMBRANE PROCESSES}

\subsection{Pressure and Concentration Driven Processes in Chemical Industry}

The best known and most utilized processes in the field of water and waste water treatment are those utilising pressure gradient as the driving force. These processes include reverse osmosis, nanofiltration, ultrafiltration and microfiltration. Similarly, concentration driven such as dialysis, donan dialysis and nondispersive solvent extraction have applied on large scale in chemical industry as well as for food and biotechnological applications.

There are numerous ways in which the membrane modules can be arranged in filtration systems. The factors influencing the choice of the option include the type of the process, the expected concentration in the streams, the volume of the processed wastes, the acceptable dose to the membrane, and desired costs of the plant. The capital costs play an important role in low and medium capacity plants, while the components of operation costs, such as energy consumption, are of less importance. For design of large capacity installations the operation costs are key elements. High investment costs for additional equipments, such as control system, washing installation, or measurement apparatuses, are reasonable when they cause a decrease of operational costs of the plant.

Currently the water production by membrane techniques has exceeded that of the traditional thermal systems thanks to the construction of new systems. One of the Europe's largest seawater reverse osmosis (SWRO) plant was realized in the 2002 at Carboneras in Spain; this plant has a capacity of $120,000 \mathrm{~m}^{3} /$ day. Moreover, many large plants are under construction. Begun in April 2003 , the Ashlkelon plant is part of a 'Desalination Master Plan' launched by Israel in 2002 to help address the country's chronic water resource problems. As stated in introduction, the design uses advanced SWRO technology (Figure 2) and state-of-the-art energy recovery systems to reduce operating costs and achieve one of the lowest water prices for this lind of operation $(\$ 0.527)$ 


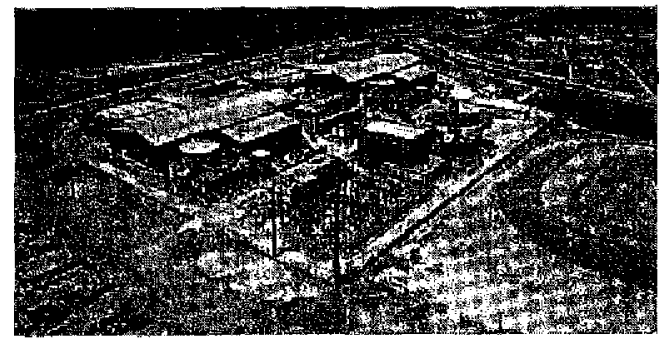

(a)

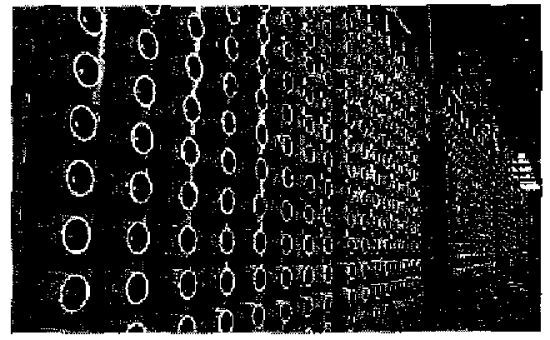

(b)

Figure 2 (a) What is claimed to be the world's largest desalination plant in Ashleelon, Israel is now providing and selling $165000 \mathrm{~m}^{2}$ of water perday using Dow's Film Tec membrane technology; (b) the Ashkelon plant contains more than 40000 Film Tec reverse osmosis membrane (reproduced from reference 3 with permission Elsevier, 2005)

$\left.\mathrm{m}^{3}\right)$. The successful operation of this plant in one of the most water-challenged areas of the world speaks of the bright future that sea-water reverse osmosis (SWRO) technology has in addressing the needs of other regions, such as China, India and Africa, which are facing growing demand and limited availability of fresh water resources [3].

Membrane bioreactor systems have, over the past ten years, emerged as an effective way of transforming various forms of wastewater into high-quality effluent that is suitable for discharge into the environment, and increasingly turning it into a reusable product. It now offers several advantages over more conventional technologies, including a smaller footprint, better solids removal and lower sludge retention time. According to industry specialists, the biggest challenge for participating companies is to convince decisionmakers in wastewater facilities about the efficiency of Membrane Bio-reactors (MBR) and the benefits they offer. For industrial applications, where stringent discharge standards are in force, MBRs give users extremely high-quality product water suitable for release into the environment to a publicly owned treatment plant or for recycling within the industrial plant's processes [4].

Leather tanning presents difficult wastewater treatment challenges. Converting raw hides into finished leather suitable for clothing, baggage and other consumer items requires large quantities of chemicals such as lime, sulfite, caustic, enzymes, salt and acid. The tanning process also produces large volumes of wastewater that must be treated before being reused or discharged in order to protect the environment and the local water supply from contamination. Two of India's largest leathertanning factories are using Koch Membrane Systems Inc's (KMS) ultrafiltration (UF) and reverse osmosis (RO) membrane technologies to increase the amount of wastewater they can reuse during processing (Figure 3). This region, within Tamil Nadu State, is one of India's primary leather tanning regions, and faces chronic water shortages, so the availability of process water for the tanning operations is of major concern to the factories [5].

A water purification system has been developed in Australia that is targeted for remote communities which have access to either contaminated surface or brackish water. It combines a hybrid ultrafiltration and reverse osmosis/nanofiltration system with a solar energy unit. In consequence, it is possible to demonstrate to global funding agencies and political organizations that desalination, coupled with renewable energy, is a very reliable and sustainable way of meeting the water needs of small communities in developing countries or indigenous people in developed countries. The modular nature of both membranes and solar panels is a natural fit, and there are very few, if any, technologies available that can reliably remove trace contaminants such as arsenic from contaminated water sources. Schematic diagram. 


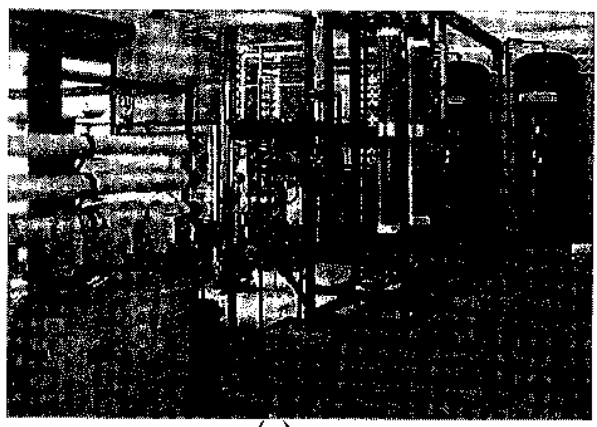

(a)

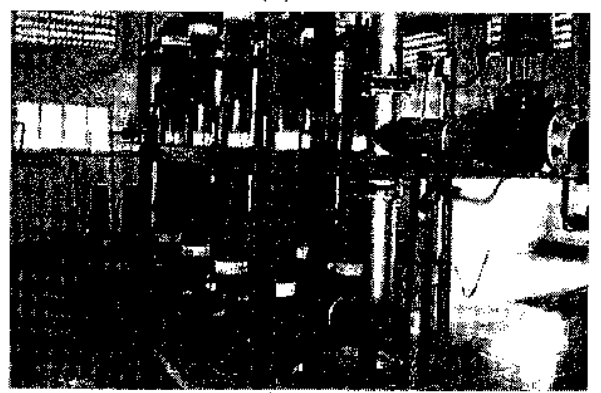

(b)

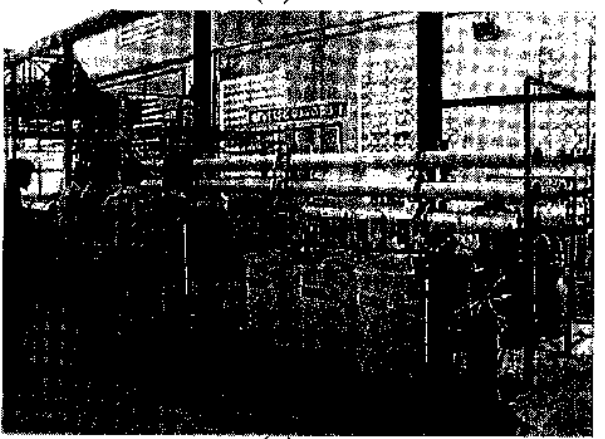

(c)

Figure 3 (a) Wastewater from the N. M Zackriah \& Co tanning operation is processed by this reverse osmosis system (far left), with pretreatment including hollowfibre ultrafiltration (right); (b) ultrafiltration cartridges provided by Koch Membrane Systems are used to reduce turbidity and remove small suspended particles in the wastewater treatment system at Eastern Chrome Tanning Corporation; (c) wastewater recovered using this reverse osmosis system at Eastern Chrome Tanning Corporation is of higher quality than tap water at the plant (reproduced from reference 5 with permission Elsevier, 2006) of the membrane configuration of the Reverse Osmosis Solar Installation (ROSI) prototype III is shown in Figure 4 [6].

\subsubsection{Fouling and Safety Aspects}

All the tanks connected with membrane installation have to be equipped with tank level meters with devices and blockades of the pumps secured against overflow. Special collectors in the floor for contaminated solutions in case of unexpected overflow have to be designed.

Fouling is one of the technical problems of membrane systems operation. The phenomenon occurs mainly during ultrafiltration or microfiltration since solutions for reverse osmosis are pretreated before they enter RO module. There are four types of fouling: dissolved solids, which can easily precipitate in the process conditions, suspended solids, biological fouling and organic nonbiological fouling, caused by carbon-based molecules fouling. The symptoms of fouling are decrease of permeate flow, increase of pressure drop across the module, and decrease of pressure in the unit. To keep the stable flux, pressure needs to be continuously increased. Usually 10\%-15\% reduction of the permeate flow should be a reason for immediate membrane cleaning, otherwise increase of pressure in the system and crystallization of salts or silica in the pores may result in the irreversible membrane structure change or damage.

\subsection{Pressure and Concentration Driven Processes in Nuclear Industry}

The nuclear industry generates a broad spectrum of low and intermediate level liquid radioactive wastes (LRWs). Various stages of management of radioactive waste as adopted in India are shown in Figure 5. These include waste characterization, treatment, conditioning, storage, disposal, surveillance/ monitoring, etc. Various options available for treatment, conditioning, storage and disposal of these wastes depending on their physical forms are also indicated. These liquid wastes may be produced continuously or in batches and may vary considerably in volume, 


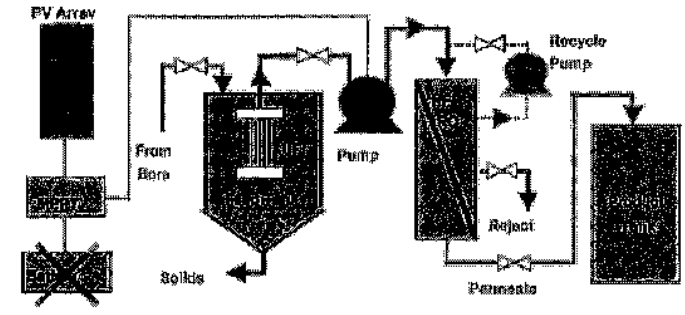

(a)

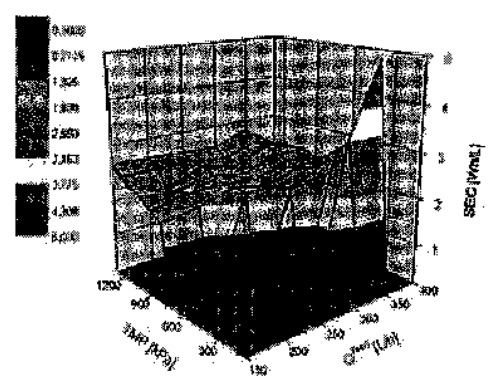

(b)

Figure 4 (a) Schematic diagram of the membrane configuration of the reverse osmosis solar installation (ROSI) prototype III; (b) specific energy consumption versus feed flow (feed) and transmembrane pressure (TMP) for a feed salt concentration of $5 \mathrm{~g} / 1$ (BW 30 membrane) (reproduced from reference 6 with permission Elsevier, 2005)

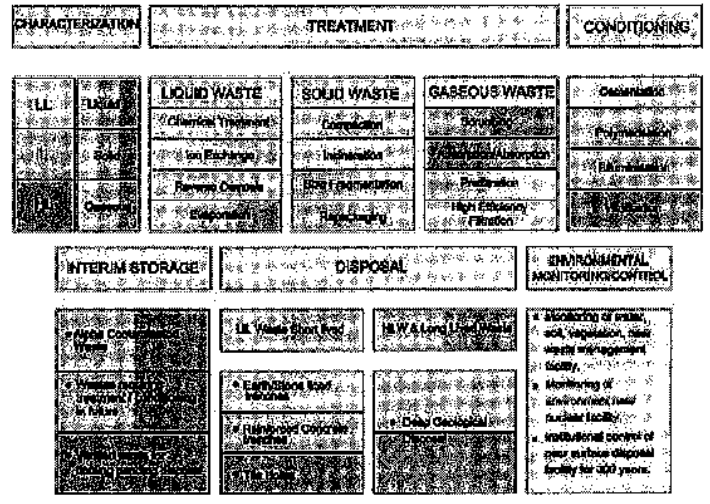

Fgure 5 Management of radioactive waste

radioactivity, and chemical composition. A wide range of treatment methods has been used throughout the industry to treat these wastes. Treatment methods for LRWs have tended to use the same conventional processes found in industrial and municipal water treatment. These processes typically include chemical treatment, adsorption, filtration, ion exchange, and evaporation. They are limited by either their inability to remove all contaminants or, in evaporation, the high operating costs involved and the large quantities of secondary solid waste produced, which means that satisfactory processing of LRWs is difficult to achieve.

Applications of membranes and anti-fouling techniques are now available making this technology viable for liquid radioactive waste processing. Recent experience with these improved systems has been quite favorable, and with proper application, the systems are dependable and possess significant processing capability.

It is common that membrane plants are automated. The automation starts up and shuts the installation, runs the cleaning cycle, adjusts the process parameters. However, some intervention of the operator in case of emergency has to be foreseen. All valves and devices remotecontrolled ought to have the possibility of manual start-up and putting in motion. Membrane installation may be integrated into the central control system in the plant where it is used. However, in case of nuclear industry it is rather recommended to design self-contained units, fully automated by simple ladder logic controller or microprocessor control. All operating parameters such as pressures, temperatures, flows, tank levels, $\mathrm{pH}$, conductivity, and specific activity are monitored and recorded. Continuous visualization of main parameters' trends is very important and helpful. The control system includes also automatic start-up and shutdown of pressure pumps, dosing pumps, as well as shutdown of the whole installation in the case of unexpected event or emergency. The exceeding the allowable operating parameters' limits should result in the start-up of appropriate blocs and alarms. 


\subsubsection{Radiation Influence on Membrane Performance}

The influence of radiation on the transport properties of different reverse osmosis composite membranes was studied by Chmielewski and Harasimowicz [7]. Reverse osmosis membranes were irradiated with a ${ }^{60} \mathrm{Co}$ source, with a linear accelerator, and were also immersed in a ${ }^{137} \mathrm{Cs}$ high activity solution, reaching absorbed dose values around $40 \mathrm{kGy}$. The results of some tests with the irradiated membranes showed that aromatic polyamide composite membranes are highly radiation resistant. This allows these membranes to be used in radioactive solutions with an activity below $3.7 \times 10^{12} \mathrm{Bg} / \mathrm{m}^{3}$, which corresponds to absorbed dose values around 30 kG $\mathrm{Gy}$. The irradiated membranes were then tested in a pilot plant with a plate-and-frame module with capacity for two membranes with an effective area of $90 \mathrm{~cm}^{2}$ each. Permselective results of irradiated membranes were compared to those of nonirradiated membranes (reference). It was observed that the performance of the samples irradiated with electronic or gamma radiation was very similar to that of the nonirradiated membranes. Tables 1 and 2 show the results of permeate flux and retention index for gammaand electron-irradiated membranes, respectively. The average value of all these samples is $\left.J_{\mathrm{V}}\right)_{\mathrm{av}}=$ $21.6 \mathrm{~L} / \mathrm{m}^{2} . h$. The highest value of the statistical dispersion is $\left.\mathrm{J}_{\mathrm{v}}\right)_{\mathrm{av}}+2 \sigma=38.8 \mathrm{~L} / \mathrm{m}^{2}$.h and the lowest value is $\mathrm{J}_{\mathrm{v}} \mathrm{j}_{\mathrm{av}}-2 \sigma=4.4 \mathrm{~L} / \mathrm{m}^{2}$.h. As indicated by the results, permeability of the gamma- and electron-irradiated samples, the dispersion values of permeability are within the limit values of the nonirradiated dispersion, proving that the variability in the results is not the consequence of radiation, but of membrane nonhomogeneity [8].

\subsubsection{Important Case Studies in India}

An attempt has been made in Bhabha Atomic Research Centre (BARC), Nuclear Recycle Group (NRG) to apply membrane process in reprocessing plant for treating various low active streams. The few important applications are discussed in brief:
Table 1 Permselective performance of gamma irradiated membranes ${ }^{\mathfrak{a}}$

\begin{tabular}{|c|c|c|}
\hline $\begin{array}{l}\text { Absorbed } \\
\text { dose (Gy) }\end{array}$ & $\mathrm{Jv}(\mathrm{L} /([\mathrm{m} 2 . \mathrm{h}])$ & $\mathbf{R}(\%)$ \\
\hline 0.25 & 28.0 & 97.0 \\
\hline 0.50 & 26.7 & 98.5 \\
\hline 1 & 30.5 & 98.6 \\
\hline 2 & 31.0 & 98.7 \\
\hline 5 & 28.5 & 98.9 \\
\hline 10 & 24.0 & 98.9 \\
\hline 20 & 20.0 & 97.7 \\
\hline Nonirradiated & 21.6 & 97.5 \\
\hline
\end{tabular}

${ }^{a}$ : Reproduced from reference 8 with permission CRC Press, 2008

Table 2 Permselective performance of electron irradiated membranes ${ }^{b}$

\begin{tabular}{lll}
\hline $\begin{array}{l}\text { Absorbed } \\
\text { dose (Gy) }\end{array}$ & $\mathrm{Jv}(\mathbf{L} /([\mathbf{m} \mathbf{2} . \mathbf{h}])$ & $\mathbf{R}(\mathbf{\%})$ \\
\hline 5 & 20.0 & \\
\hline 10 & 26.7 & 97.2 \\
15 & 18.7 & 97.5 \\
20 & 14.0 & 97.4 \\
25 & 20.0 & 97.0 \\
Nonirradiated & 21.6 & 97.4 \\
\hline
\end{tabular}

b: Reproduced from reference 8 with permission CRC Press, 2008

In waste immobilisiation plant, BARC, Mumbai, India, a reverse osmosis plant of capacity $100 \mathrm{~m}^{3}$ / day using polyamide membrane in spiral wound configuration is in operation for treatment of lowlevel $\left(37-3.7 \times 10^{6} \mathrm{~Bq} / \mathrm{L}\right.$ ) waste at Trombay (Figure 6a). The volume of waste is normally reduced by a factor of 10 and decontamination factor of 8-10 is achieved in this process. In another pilot plant, a low level radioactive waste containing alpha and beta activity was carried in reprocessing plant, BARC Tarapur, India (Figure 6b).The results of the RO studies carried out with low active waste indicated that DF values for alpha range from 610 , and for beta, from 6-15. Nitrates and total dissolved solid (TDS) were also strongly rejected by RO. The results from the permeate solution show that after passing $60,000 \mathrm{~L}$, the performance of the pilot plant was quite promising. In once 


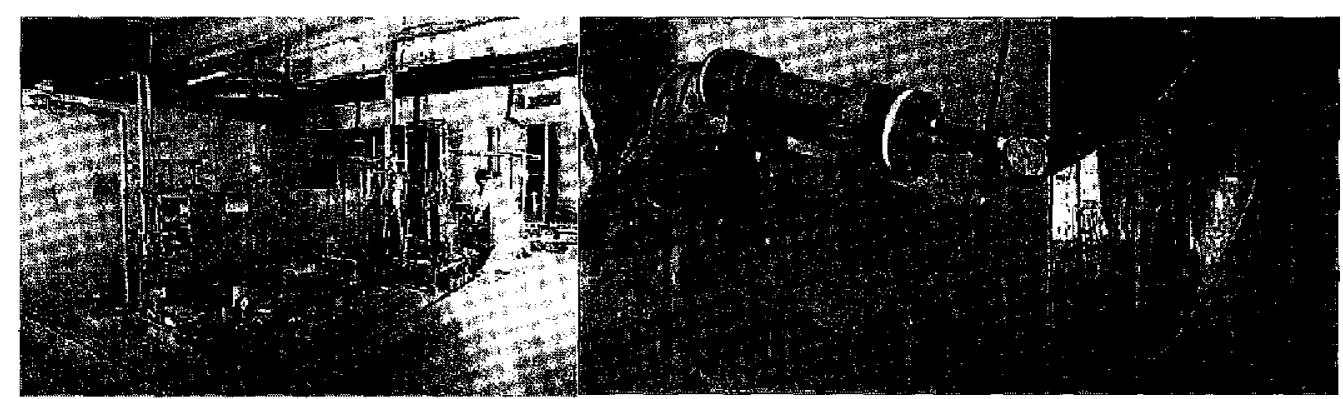

(a)

(b)

Figure 6 (a) Reverse osmosis plant at BARC, Trombay, Mumbai, India; (b) reverse osmosis (RO) set-up installed at delay tank site in PREFRE plant, BARC, Tarapur (reproduced from reference 9 with permission CRC Press, 2008)

through mode, good permeate quality was maintained, whereas alpha and beta activities of the concentrate reached $10^{-4} \mathrm{mCi} / \mathrm{L}$ and $10^{-3} \mathrm{mCi} /$ $\mathrm{L}$, respectively, and TDS levels surpassed 15,000 ppm. The life time of this RO module is evaluated in order to check for any damage or hot spot (a spot which gives radiation dose due to accumulation of radionuclide) on the module. However no hot spot was observed and module gave satisfactory performance as permeate quality was up to the mark [9].

Low-active liquid waste (i.e., condensate, regenerant, and detergent) generated in reprocessing plants is subjected to electrodialysis for concentration of radioactive cations into a very small volume, thus rendering a large portion of the waste disposable and environment friendly $\left(5 \times 10^{-5} \mathrm{mCi} / \mathrm{L}\right.$ gross beta activity). For this purpose, an electro-membrane cell containing an ion-exchange membrane in its central compartment was designed and fabricated in the BARC laboratory. Most of the radioactivity from the low-level radioactive effluents could be removed by Electrodialysis (ED). Greater decontamination factor (DF) was achieved for cesium than for ruthenium due to the nonionic nature of the latter. The concentrate streams generated during electrodialysis contained $0.005-$ $0.05 \mathrm{mCi} / \mathrm{L}$ of $\mathrm{Cs}-137$, and the volume reduction factor achieved in the electrodialysis operation was ca. 10 [9].

Uranous nitrate $\left[\mathrm{U}\left(\mathrm{NO}_{3}\right)_{4}\right]$ solution is used for the quantitative reduction of plutonium from loaded tributyl phosphate (TBP) phase. Membrane cell technology was investigated for the production of $100 \%$ uranous nitrate solution, which is to be used in the partition cycle of the PUREX process (plutonium uranium reduction extraction process) in the fuel reprocessing plant. A study was carried out at the BARC to obtain $100 \%$ uranous nitrate solution using a membrane based electrolytic cell. The membrane was used for over 5 years in nitric acid and hydrazine medium without any apparent damage. It offered high chemical resistance and mechanical strength. In each batch operation, the percentage conversion to uranous nitrate was $100 \%$. The $100 \%$ uranous nitrate solution generated was utilized for the plant process. Several kilograms of uranous nitrate have been produced in the reprocessing plant using this technique [9].

In view of the radiological safety the personal contact with operating installation should be minimized. The location of data acquisition and control systems has to be planned in separate room, away from places of potential contamination. However, the necessity of eventual periodic sampling has to be taken into account, too. The sampling points have to be located in the places with easy operator access and arranged in a way eliminating leaks and contamination [10$11]$.

All polymeric membranes and modules have admissible temperature of operation. For most of them this temperature is $40^{\circ} \mathrm{C}$, only for inorganic materials this temperature is much higher. In case 
of reverse osmosis there is a possibility of retentate and permeate temperature growth caused by the circulation under high pressure. The continuous temperature control of the streams with upper alarm has to be predicted. The systems collecting the excess heat (radiators, ribbed pipelines) allowing.intensive cooling have to be designed [10-11].

\subsubsection{Membrane Cleaning and Scaling Control}

During concentration of radioactive waste by pressure-driven membrane processes, such as reverse osmosis, the solubility limits of some dissolved salts can be exceeded. These salts precipitate on membrane surface or in other parts of the plant causing the damage of the membrane or severe corrosion of the elements of installation. The most common compounds that precipitate easily causing scaling are calcium salts $\left(\mathrm{CaCO}_{3}\right.$, $\mathrm{CaSO}_{4}, \mathrm{CaF}_{2}, \mathrm{CaHPO}_{4}$ ), barium and strontium sulfates, and silica and magnesium carbonate. The methods of scale minimization include a proper pretreatment (acid injection to reduce carbonates or water softening by lime or lime soda, ion exchange or removal of bivalent ions with nanofiltration) and antiscalant addition. The scale inhibiting compounds are injected in the parts of the installation with the high risk of scale formation. These places have to be specified in the project design of the plant. Antiscalants delay precipitation by formation of microcrystals with low agglomeration abilities that interfere with crystallization of the other salts and are responsible for scaling. The most common scale inhibiting chemicals are polyphosphates, polycarbooxilites, polymalonates, and polyacrylates. In Chalk River Laboratories the antiscalant agent effectively preventing scaling in RO plant was Pretreat Plus (King Lee Technologies, San Diego, California) [10-11], at Institute of Atomic Energy in Poland in threestage RO plant the sodium hexametaphoshpate (Calgon) was chosen. To prevent scaling in RO pilot plant designed and operated by ANSTO antiscalants AS-1000 (phosphinocarboxylic acid) and AS-1300 (polycarboxylic acid) were used [10-11].
The periodic cleaning of the membranes exposed to the action of foulants and scalants present in the wastes is necessary. The frequency of the cleaning depends on the composition of the wastes; the necessity is recognized from the pressure drop or rapid flux decrease. If the flux drops by several percent, the membrane has to be restored. The volume of the cleaning solutions should be as small as possible, to minimize the amount of secondary wastes. The selection of the cleaning agents and their concentration depends on the membrane and on the kind of foulants present in the waste. Manufacturers of the membranes usually recommend some cleaning solutions, acidic or basic and detergents, which have to be tested during pilot plant experiments. The most popular agents are citric acid, sulphuric acid, sodium hydroxide, sodium tripoly phosphate, sodi u m ethylenediaminetetraacetate, and ethylendiaminetetraacetic acid (EDTA). These compounds are relatively inexpensive and widely applied, however sometimes specially prepared membrane manufacturers' formulations sometimes superior and worthy of consideration. Such reagents, however, themselves are very good centers of nucleation and initialization of fouling and scaling. So subsequent fouling can be even more severe after restoration of the membrane. Various cleaning agents are available in the market. They can minimize the production of secondary wastes because they can clean the membranes very effectively. For polymeric RO membranes applied in Chalk River Laboratories, for example, good results were obtained using Memclean, alkaline detergent containing EDTA [10-11]. For cleaning ceramic membranes used at the Institute of Nuclear Chemistry and Technology (INCT), Warsaw, the P3-ultrasil, Henkel EKOLAB, was effective. On the other hand, laboratory preparations (e.g., alkali and acid based solutions) also proved very useful [10-11]. 


\subsection{WORLD SCENARIO OF MEMBRANE TECHNOLOGY IN CHEMICAL AND NUCLEAR TECHNOLOGY}

During the last 5-10 years membrane technology has been gradually introduced into nuclear power plants for treatment of low level radioactive wastes (LRWs). Many power plants in the United States of America, for example, have traditionally treated low level liquid effluent by direct evaporation of the liquid waste, by conventional filtration and ion exchange, or by combination of these. The common limitation of these processes is that they generate significant quantities of radioactive solid waste to be disposed of. Furthermore, the treated liquid effluent is not pure enough for environmental discharge or recycling. Some of large scale applications of membrane processes in chemical industry can be referred in a specialized report published by IAEA (International Atomic Energy Agency) in 2004 [12].

In most of these cases, the reverse osmosis units actually utilize nanofiltration membranes to allow passage of boric acid to the permeate side while rejecting any residual dissolved radioactivity. This allows the permeate to either to be discharged to the environment or recycled. This represents the most extensive use of reverse osmosis ( or nanofiltration) in nuclear plants [12].

Considerable pioneering efforts in this respect were made at AECL's Chalk River Research Laboratory, beginning in the 1970s. The objective was the development and acquisition of a two stage reverse osmosis system with a productivity of $28000 \mathrm{~m}^{3} / \mathrm{a}$. The concentrated reject (reject after the last module in series) from the reverse osmosis system was to be bituminized (process of fixing activity in solid form with bitumin). Research and exploratory work was conducted which enabled design of a full scale system consisting of crossflow microfiltration, spiral wound reverse osmosis (first stage), and tubular reverse osmosis (second stage), as shown in Figure 7a. The system processed approximately $2200 \mathrm{~m}^{3}$ of LRW annually,

Membrane installation, capacity of $\sim 1 \mathrm{~m}^{3} / \mathrm{h}$ pure permeate, was composed of three stages of reverse osmosis preceded by pretreatment with polypropylene depth filters. The first two stages were used for purification, and the third one for final concentration. Two types of spiral-wound RO modules were used in the installation and they work under a pressure of $20 \mathrm{bar}$ and with high salt rejection, higher than $99 \%$. The membrane was manufactured from cross-linked fully aromatic polyamide composite. The view of the plant is shown in Figure 7b.

Membrane installations operated in nuclear industry are pressure-driven systems; majority of them are reverse osmosis plants. Uncontrolled growth of operation pressure may result in module damage and valves' leaks resulted in contamination hazard. The selection of appropriate pumps and security devices can avoid the danger of pressure overgrowth and its detrimental implications. The security valves' outlets have to be connected with existing waste distribution systems to direct the eventual leaks to the waste collecting tanks [1011].

\subsection{FUTURE PROGRESSES AND CHALLANGES IN MEMBRANE ENGINEERING}

Practically, there is a lot of opportunities for membrane separation processes in all areas of the modern industry. The most interesting developments for industrial membrane technologies are related to the possibility of integrating various membrane operations in the same industrial cycle, with overall important benefits in terms of product quality, plant compactness, environmental impact, and energetic aspects. At present, redesigning important industrial production cycles by combining various membrane operations suitable for separation and conversion units, thus realizing highly integrated membrane processes, is an attractive opportunity because of the synergic effects that can be attained [13]. In a latest study, Baker [1] has emphasized on the current research needs in the membrane separation industry. The study was performed by a group of six membrane experts representing various fields of membrane technology. Membrane separations were divided into seven application areas. This report 


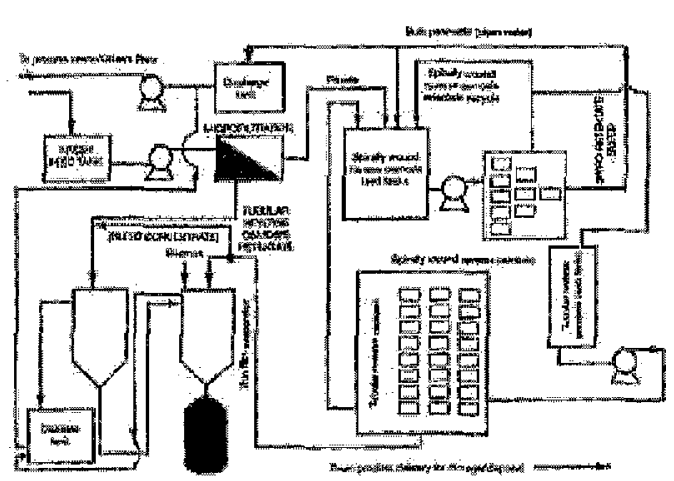

(a)

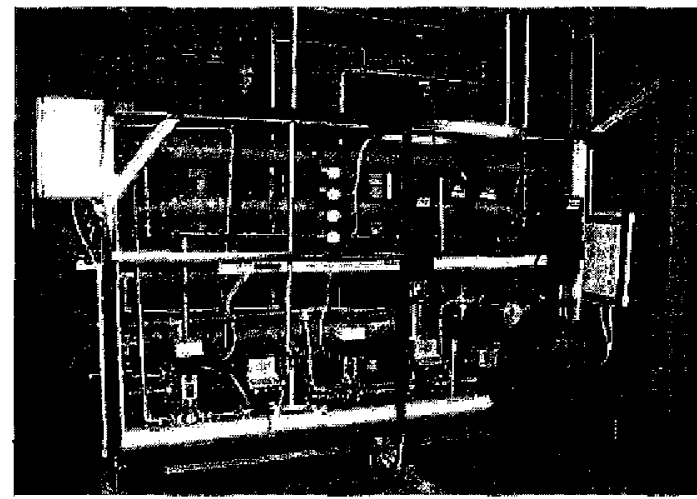

(b)

Figure 7 (a) Integrated plant for processing mixed LRW (reproduced from reference 2 with permissin IAFA 2005); (b) three-stage reverse osmosis plant for radioactive waste processing at Institute of Atomic Energy inSwierk (Poland)

summarize the key results from this effort and provides a perspective on the success of the study and its impact on membrane separations. As an outset, this report has stated that considerable progress has been made in a number of key areas, with some important and unanticipated developments. This type of technology assessment report can prove to be important in setting up the directions for research and development, both for individual scientists and engineers and for the broad membrane community.

In forthcoming projects is the realization of a desalination plant between Red Sea and Dead Sea, using the process of hydrostatically supported reverse osmosis to provide a desalinated seawater (Figure 8a) . Hydrostatic energy potential of 300 $m$ elevation difference between Red Sea and Dead Sea will-be used for desalination by hydrostatically supported SWRO. On completion, this plant will produce $26 \mathrm{~m}^{3} / \mathrm{s}$ of water. The need for even more cost-effective and efficient systems for water recovery, was, and continues to be, the driving force for the research and development in RO technology.

Among latest membrane techniques on commercial scale, liquid-liquid extraction has also been employed on a commercial scale in membrane contactors to remove environmentally toxic species from wastewater before incineration. Photograph of such a system is shown in Figure 8b. Multiple banks of contactors are used in the system. The solvent used for extraction is returned to the chemical process that produces product in aqueous stripping solution. Metal separation is the thrust area where membrane contactors are proving to be better than conventional methods. Applications of membrane contactor for actinide separations are emerging area in this field and several research groups are worlking in different countries [14-15].

$\mathrm{MCs}$ are being applied in various areas and proved to be quite cost effective also. In this direction, Korean Electric Power Institute (KEPRI) has installed Liqui-Cel Membrane Contactors in the Kori nuclear power plant in South Korea. The membranes have been in operation since 2000 and have successfully met the rigorous demands of the nuclear power industry. The water is continuously recirculated through the membrane contactor system in an effort to keep the dissolved oxygen level low. Dissolved oxygen is controlled to very low levels in this system in order to prevent corrosion of piping and equipment. Dissolved nitrogen is also controlled to prevent the formation of Carbon 14. C-14 being radioactive isotope can create radiation dose to the plant workers $[10,16]$. Figure $8 \mathrm{c}$ shows the schematic of the unit used for this purpose.

In the field of analytical applications, these techniques exhibit high selectivity, and they concentrate analytes during the separation process. For this reason, these techniques have 


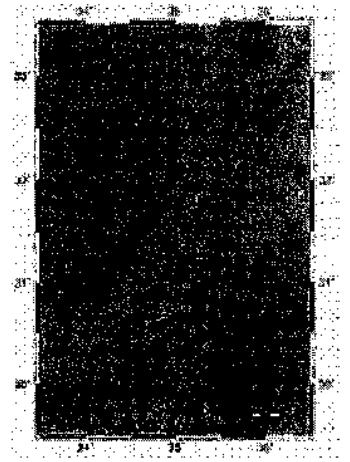

(a)

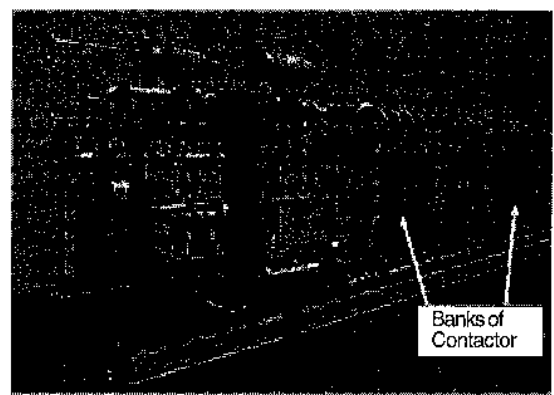

(b)

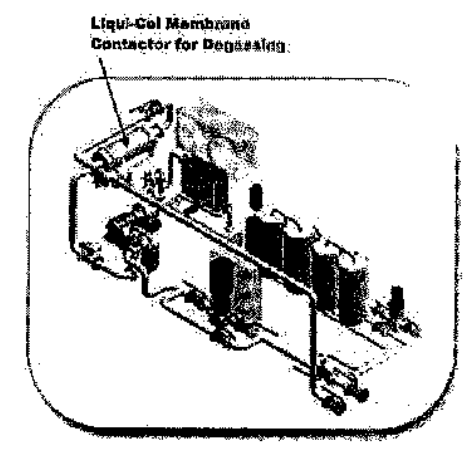

(c)

Figure 8 (a)The three alignments suggested for the realization of a sea reverse osmosis (SWRO) desalination plant between Israel and the Hashemite Kingdom of Jordan (from http:// www.mfa.gov.il/mfa);(b) membrane contactors for liquid-liquid extraction; (c) three dimensional front diagram of degassing equipment at Korea nuclear power plant for removal of dissolved oxygen and nitrogen (to avoid radioactive $\mathrm{C}-14$ ) production) from feed water (reproduced from reference 12 with permission CRC Press, 2008)

undergone significant development in the last decade used for analytical sample preparation, due to its advantages over conventional sample preparation techniques. In future, membrane techniques will replace conventional analytical techniques due to its merits over routine techniques [17]. In a interesting application, these membranes could be also used to remove $\mathrm{CO}_{2}$, which is a waste product of human metabolism, from the atmosphere of a self-contained spacecraft. Moreover, these or similar membranes could also offer possible solutions to the problem of the $\mathrm{CO}_{2}$ emission control on the earth [18].

\subsection{CONCLUSION}

The membrane separation processes listed are at different stages of development and implementation. Despite some technical and process limitations membrane techniques are very useful methods for the treatment of different types of effluents. They are already proven in chemical industry for the treatment of various effluents. They can be applied in nuclear centers processing low- and intermediate-level liquid radioactive wastes or in reprocessing plants. All the methods reported in the chapter have many advantages and can be easily adapted for actual, specific needs Some of them are good pretreatment methods; the other can be used separately as final cleaning steps, or can be integrated with other processes. Membrane methods can supplement or replace techniques of distillation, extraction, adsorption, ion exchange, etc.

Also, advances in membrane processes for both chemical and nuclear waste processing with respect to current global situation of membrane processes are also reported.

\section{REFERENCES}

[1] Balker, R.W. 2010. Research Needs in the Membrane Separation Industry: Looking Back, Looking Forward. Journal of Membrane Science. 362:134-136.

[2] Pabby A.K, and A.M. Sastre. 2008. Membrane Applications in Industrial Waste Management (including nuclear), Environmental Engineering and Future Trends in Membrane Science: Introduction. In Handbook of Membrane Separations: Chemical, Pharmaceutical, Food and Biotechnological Applications. 
Edited by A. K. Pabby, S, S. H. Rizvi and A. M. Sastre. New York. USA: CRC Press. 823825.

[3] Atkinson S. December 2005. World's Largest Desalination Plant Begins Operating in Israel, Membrane Technology. 12: 9-10.

[4] Atkinson S. February 2006. Research Studies Predict Strong Growth for MBR Markets. Membrane Technology.2:8-10.

[5] Atkinson S. January 2006. UF and RO Technologies Help Tanneries in India Treat Wastewater. Membrane Technology. 1: 10-11.

[6] Atkinson S. 2005. Membranes and Renewable Energy - A New Era of Sustainable Development for Developing Countries. Membrane Technology. 11: 610.

[7] Chmielewski A. G. and M. Harasimowicz. 1997. Influence of Gamma and Electron Irradiation on Transport Properties of Nanofiltration and Hyperfiltration. Membranes. Nukleonik. 42:857-862.

[8] Sancho. M., J. M. Arnal, G. Verdú, and J. Lora. Reverse Osmosis-Based Treatmentof Radioactive Liquid Wastes Generated in Hospital Facility and in Steel Industry:Case Studies. In Handbook of Membrane Separations: Chemical, Pharmaceutical, Food and Biotechnological Applications. Edited by A. K. Pabby, S. S. H. Rizvi and A. M. Sastre. New York. USA: CRC Press. 919-932.

[9] Pabby, A. K., Gupta, S. K., Sawant, S. R., Rathore, N. S., Janardan, P., Changrani R. D. and Dey, P.K. 2008. Evaluation of Membrane-based Processing of Radioactive Nuclear Plant Waste: Case Studies. In Handbook of Membrane Separations: Chemical, Pharmaceutical, Food and Biotechnological Applications. Edited by A. K. Pabby, S. S. H. Rizvi and A. M. Sastre, New York. USA: CRC Press. 933-943.

[10] Grazzyna Zakrzewska-Trznadel.2008. Radioactive Waste Processing: Advancement in Pressure-Driven Processes and Current World Scenario. In Handbook of Membrane Separations:
Chemical, Pharmaceutical, Food and Biotechnological Applications. Edited by A. K. Pabby, S. S. H. Rizvi and A. M. Sastre, New York. USA: CRC Press. 843-882.

[11] Handbook of Membrane Separations: Chemical, Pharmaceutical, Food and Biotechnological Applications. 2008. Edited by Pabby, A. K., Rizvi S. S. H. and Sastre A. M. New York, USA: CRC Press.

[12] IAEA Technical Reports Series No. 431. 2005. Application of Membrane Technologies for Liquid Radioactive Waste Processing. IAEA, Vienna: 1-145. (http:// www.iaea.org/Publications/index.html).

[13] Pabby, A. K. November 2008. Membrane Techniques for Treatment in Nuclear Waste Processing: Global Experience. Membrane Technology. 9-13.

[14] B. M. Misra and V. Ramachandhran. 2008. Treatment of Radioactive Effluents: Introduction, Fundamentals, and Scope of Different Membrane Processes. In Hand book of membrane separations: Chemical, Pharmaceutical, Food and Biotechnological Application. Edited by A. K. Pabby, S. S. H. Rizvi and A. M. Sastre. New York. USA: CRC Presss. 827-842.

[15] Pabby A. K., Roy, S. C., Sonawane J.V., Alguacil F. J., and Sastre A. M. 2008. Strip Dispersion Technique: Applications for the Strategic and Precious Metal Separation and Treatment of Waste Water Streams. In Handbook of Membrane Separations: Chemical, Pharmaceutical, Food and Biotechnological application. Edited by A. K. Pabby, S. S. H. Rizvi and A. M. Sastre. New York. USA: CRC Presss. 1057-1071.

[16] Liqui-Cel: Wolsung Nuclear Power Plant in South Korea Uses Liqui-Cel® MembraneContactors for Dissolved Oxygen Removal to Prevent Corrosion (web site: http://www.liqui-cel.com/) (visited on 1610-10)

[17] Pabby A. K. and Sastre, A. M. 2009. Membrane Techniques in analytical Applications: Developments and Advances. In Encyclopedia of Analytical Chernistry. Edited by Robert Meyers and 
Zeev Alfassi. New York, USA: John Wiley. 13: 1-34.

[18] Enrico Drioli and Enrica Fontananova, Future Progresses in Membrane Engineering. 2008. In Handbook of
Membrane Separations: Chemical, Pharmaceutical, Food and Biotechnological Application. Edited by A. K. Pabby, S. S. H. Rizvi and A. M. Sastre. New York. USA: CRC Presss. 1131-1143. 